\title{
Improvement of Torque-and-Drag Modeling in Long-Reach Wells
}

\author{
Seyed Ahmad Mirhaj \\ Petroleum Engineering Department, University of Stavanger \\ 4036 Stavanger, Norway \\ Tel: 47-518-321-32 E-mail: s.ahmad.mirhaj@uis.no
}

Eirik Kaarstad

Petroleum Engineering Department, University of Stavanger 4036 Stavanger, Norway

Tel: 47-518-318-35Ｅ-mail: eirik.karstad@uis.no

Bernt S. Aadnoy

Petroleum Engineering Department, University of Stavanger

4036 Stavanger, Norway

Tel: 47-518-322-56 E-mail: bernt.aadnoy@uis.no

Received: July 6, 2011

Accepted: September 5, 2011

doi:10.5539/mas.v5n5p10

\begin{abstract}
Torque and drag modeling is regarded as an invaluable process to assist in well planning and to predict and prevent drilling problems. It discusses how to use torque and drag calculations and measurements to plan long-reach well profiles, to execute drilling operations that minimize torque and drag effects and to monitor hole cleaning.

In this study a general overview on most of the available literature on the subject is presented. Different models that have been developed for torque and drag predictions along with pros and cons of the models will be discussed. The application of our new fully 3-dimensional analytical friction model will be presented. Moreover a new criterion has been implemented into the new model in order to capture the effect of weight in the horizontal section especially when BHA is dragged into/out of the wellbore. The model validity will be checked by applying the model for two field cases of ERD wells in North Sea. Field cases also demonstrate the importance of buoyancy effects, tripping speed, hydraulic piston force, pipe stiffness as well as well path effects.
\end{abstract}

Keywords: 3-D wellbore friction, Curved pipe section, Straight pipe section, Torque and drag, Friction coefficient

\section{Introduction}

The development of longer reach wells became very important not only to drain older fields more efficiently but also to reduce the number of offshore platforms on new development projects. [Aadnoy 1998]

There are number of causes for excessive torque and drag, including tight-hole conditions, sloughing shale, key seats, differential sticking, cuttings build-up caused by poor hole cleaning and sliding wellbore friction. Conversely, in wells with good hole conditions, the primary source of torque and drag is sliding friction [Johancsik 1984, Sheppard 1987, Lesage 1988].

Torque and drag (T\&D) modeling is required in well planning because it helps to predict and prevent drilling problems that might occur during the drilling process. Although T\&D software has existed since the 1990s, some confusion still exists over the validity of the models that are used to characterize drilling operations, especially as we extend the length of modern horizontal wells.

The increased torque and drag could be due to ineffective hole cleaning, hole instability, differential sticking and solids in the mud system or the wellbore geometry. [Sheppard 1987, MacDonald 1987, Lesage 1988 and Brett 1989]. 


\section{Review of Previous Works}

Torque and drag modeling has been originally started with Johancsik et al. (1984) and later put in a standard differential form by Sheppard et al. (1987). Because of the simplicity and being user friendly, it has been extensively used in the field and industry applications.

All models discussed here are soft-string models. In other words the drillstring is assumed to be like a cable and forces due to bending moments have not been considered to affect the normal forces and thus friction. This is fairly good assumption as it may contribute small normal forces on the overall force balance. Moreover, although in reality the friction coefficient is not really a single coefficient. It is more a fudge factor that lumping other different factors. These factors are including mud system lubricity, cuttings bed, key seats, stabilizer and centerlizer interaction, differential sticking, dogleg severity (known and hidden), hydraulic piston effect, hydrodynamic viscous force etc.

Johancsik assumed both torque and drag are assumed to be caused entirely by sliding friction forces that result from contact of the drillstring with the wellbore. He then defines the sliding friction force to be a function of the normal contact force and the coefficient of friction between the contact surfaces based on Coulomb's friction model. He wrote the force balance for an element of the pipe considering the fact that the normal component of tensile force acting on the element contributing to the normal force. Of course this is not the case for a straight section like in hold section.

The normal force is given by the equation:

$$
F_{n}=\left[\left(F_{t} \Delta \alpha \sin \theta\right)^{2}+\left(F_{t} \Delta \theta+W \sin \theta\right)^{2}\right]^{1 / 2}
$$

The above equation is then used to derive the equation for the tension increment which is used for drag calculations:

$$
\Delta F_{t}=W \cos \theta \pm \mu F_{n}
$$

Where the plus and minus sign allows for pipe movement direction whether running in or pulling out of the hole.

And for the torsion increment which is used for torque calculations:

$\Delta M=\mu F_{n}$

Later Sheppard et al. (1987) put the Johancsik's model into standard differential form and also took the mud pressure into account that acts upward when the drillstring is running inside hole.

Du and Zhang (1987) illustrated two field cases using catenary trajectories drilled in China. Liu et al. (2007, 2009), Han (1987, 1997) and Liu (2007) discussed the methods for planning a catenary profile.

Maidla and Wojtanowicz (1987, a), Lesage et al. (1988), Brett et al. (1989), Lesso et al. (1989), Aarrestad (1990), Wilson et al. (1992), Alfsen et al. (1993), Eek-Olsen et al. (1993, 1994) and Rae et al. (2005) all performed a field case study torque and drag analysis with the Johancsik's model (1984) with evaluating effect of different parameters.

Maidla and Wojtanowicz (2000) used an experimental design to mimic real hole situation to measure friction factor for different mud types (i.e. oil-based or water-based mud) and different formation types.

He and Kyllingstad (1995) discussed about the paper on relationship between torque and helical buckling in drilling.

Maidla and Wojtanowicz $(1987$, b) also presented a new procedure for wellbore drag prediction. The procedure employed iteration over directional survey points, numerical integration between the stations and mathematical models of axial loads within pipe movement in the wellbore. The model considers some new effects such as hydrodynamic viscous drag, contact surface and dogleg angle.

Luke and Juvkam-Wold (1993) investigated the effect of sheave friction in the block and tackle system of drilling line and they conclude that hook only is a function of deadline tension, number of lines between the blocks as well as sheave efficiency and block-movement direction. It also depends on the type of deadline sheave whether active or inactive.

Feiber et al. (1999) developed a computer model for on-line torque and drag analysis which he assessed the borehole conditions based on calculating of the friction factors incrementally which starts calculating the hook load and torque bottom-up at each node with the bottom-end boundary conditions to be DWOB and DTOB and changing the friction factor until the calculated surface load matches the measured value. Fig. 1 shows the different sections of the pipe in the wellbore. 
Anston (1998) addressed techniques to minimize torque and drag in the wellbore including both mechanical and chemical methods.

Aarrestad (1994) discussed application of catenary well profile in a well in North Sea that has been introduced by Sheppard (1987) and later changed it to modified catenary profile by Alfsen (1993) and Aadnoy (2006) which is a hyperbolic function well profile and the drillstring is hanging from two fixed points. This is like an ambitious profile that almost has zero contact force with the hole wall. The modified catenary curve demands a strict adherence to low dogleg severity in the shallow part of the well and a slow increase in build rate as depth increases. Moreover McClendo and Anders (1985) studied the catenary well profile and demonstrated its advantages over conventional methods. This development became very important not only to drain older fields more efficiently, but also to reduce the number of offshore platforms in new development projects.

Payne et al. (1998) describes concerns regarding torque and drag considerations including buckling, cuttings bed and wellbore trajectory.

Ho (1988) improved previous soft-string model into somehow stiff-string and showed that for most parts of the drillstring the stiffness effect like drillpipe, heavy-wall drillpipe is minor and for drillcollars is major and has to be taken into account.

Opeyemi et al. (1998) perform both well planning and drillstring design by using a torque and drag analysis with considering all constrains might be encountered during planning phase. It also suggests that the torque and drag model which is used for planning and modeling processes should be updated with the dynamics of the field operation by performing drilling, tripping and frictional sensitivity analysis. This will ensure more precise understanding of wellbore/drillstring interactions from surface to TD.

An analysis of combining surface weight-on-Bit and surface torque i.e. (SWOB, ST) and downhole measurement of these values i.e. (DWOB, DTOB) gives a clearer picture of the drilling downhole. In this case the poor bit performance could be distinguished from other problems related to cuttings transport and differential sticking and thus the necessary action can be taken.

A review over design considerations and potential problems was presented by Guild et al. (1995) and later in 1996 the complete well design process had been described by Aadnoy and completed in 1998 by him. Aadnoy derived all equations for different sections of the wellbore profile including straight inclined sections and drop-off and build-up sections. He also derived the equation for a side bend to right or left in the wellbore geometry. Finally the modified catenary profile issues had been addressed.

Schamp et al. (2006) suggested some industrial methods to reduce torque in the wellbore during drilling. He introduced two sources of torque in the wellbore: the frictional resistance between the rotating drillstring and the casing/borehole and the bit/stabilizer torque and proposed some methods to mitigate the frictional resistance Mason et al. (2007) pointed out different minor effects that have to be considered in the soft-string models in order to have a more realistic model. One of these factors is hydrodynamic viscous force. Another is tortuosity effect. Although the preplanned well is a smooth path, the crooked profile will be resulted in reality. For this reason the model has to take this effect into account. A crooked well path shows higher torque and drag values. The buckling of the tubular should also be taken into account in order to have a sense of excessive drag limit which may put the string in compression such that it buckles.

Aadnoy (2006) has extensively derived the mathematical equations for catenary well profile. He then applied the developed equations into a field case study for an ultralong well with $10 \mathrm{~km}$ extended-reach and little friction reduction observed in comparison with conventional well profile as entrance to the catenary profile at the top creates extra friction.

Aadnoy (2008) generalized the equations for different sections of the wellbore and the status of the pipe either moving up or down in order to be applied simpler.

Kaarstad and Aadnoy (2009) also studied experimental investigation of friction factor dependence on temperature and they observed an increase in friction coefficient with temperature and a temperature dependent friction coefficient model was presented. Mitchell $(2008,2009)$ has used the previously torque and drag model and has been formulated such that the stiffness of the pipe will be included in the pipe. In his mathematical study he assumed the pipe as a beam member and calculated the bending moment over this beam as a result of forces acting on the beam. 


\section{Torque and Drag Models and Application of New 3-D Model}

We have used two field case studies to analyze torque and drag predictions with three different models have been developed. The first model is Johancsik (1984) which is still applicable in the torque and drag simulators in the industry. The second model is the modified Texas A \& M model. It was a 2-D model that we changed it into 3 -D in order to be applicable for side bends as well as build/drop sections. The third model is a new analytic fully 3-dimensional torque and drag model was developed by Aadnoy, Fazaeli and Hareland (2009) which incorporates many more features. It introduces one single term, dog-leg severity, for both build/drop and side bend sections. With all these three models which seem to be the only available models up to now, we have analyzed two wells that has been drilled in North Sea, Norway. Hereafter we briefly point out these effects with hook load and torque plots for drilling-ahead conditions.

In summary the new 3-D model is as follows: The model is divided into two sections of pipe-rotation and no pipe-rotation. The pipe rotations equations are for the cases which both axial and rotational motion of the pipe have been considered.

\subsection{Axial motion only:}

Drag for straight inclined wellbore sections without pipe rotation

$$
F_{2}=F_{1}+\beta \Delta L W\{\cos \alpha \pm \mu \sin \alpha\}
$$

Drag for curved wellbore sections without pipe rotation

$$
F_{2}=F_{1} e^{ \pm \mu\left|\theta_{2}-\theta_{1}\right|}+\beta W \Delta L\left\{\frac{\sin \alpha_{2}-\sin \alpha_{1}}{\alpha_{2}-\alpha_{1}}\right\}
$$

\subsection{Rotational motion only:}

Torque for straight inclined wellbore sections without axial pipe motion

$$
T=\mu r \beta W \Delta L \sin \alpha
$$

Torque for curved wellbore sections without axial motion

$$
T=\mu r N=\mu r F_{1}\left|\theta_{2}-\theta_{1}\right|
$$

\subsection{Combined axial motion and rotation:}

The angle between the axial and tangential velocity is:

$$
\psi=\tan ^{-1}\left(\frac{V_{h}}{V_{r}}\right)=\tan ^{-1}\left(\frac{60 \cdot V_{h}(m / s)}{2 \pi \cdot N_{r}(r p m) \cdot r(m)}\right)
$$

For straight pipe sections:

$$
\begin{aligned}
& F_{2}=F_{1}+\beta W \Delta L \cos \alpha \pm \mu \beta W \Delta L \sin \alpha \sin \psi \\
& T=\mu r \beta W \Delta L \sin \alpha \cos \psi
\end{aligned}
$$

For curved pipe sections:

$$
\begin{array}{r}
F_{2}=F_{1}+F_{1}\left(e^{ \pm \mu\left|\theta_{2}-\theta_{1}\right|}-1\right) \sin \psi+\beta W \Delta L\left\{\frac{\sin \alpha_{2}-\sin \alpha_{1}}{\alpha_{2}-\alpha_{1}}\right\} \\
T=\mu r N=\mu r F_{1}\left|\theta_{2}-\theta_{1}\right| \cos \psi
\end{array}
$$

\section{New Criteria in New 3-D Model}

The new model assumes weightless pipe. This means that the pipe is always tensile forces are considered to be dominant over weight of the pipe and thus the pipe could be considered weightless. This would not be an accurate assumption for the heavy sections of the drillstring i.e. BHA.

Fig. 3 shows the position of the pipe in the wellbore in a side bend. Drillpipe will lie on low side of the wellbore wall when weight is dominant whereas it lies on the sidewall if the tension is dominant. In other words, the 
weight of the pipe appears to be dominant when BHA is moving inside a bend. Because In almost all cases the BHA are in compression and the tensile force is not high enough to overcome the weight of the pipe and keeps the pipe up in the bend (Fig. 3).

Moreover, the stiffness of the BHA is a concern especially in this case that there are many stabilizers in the BHA and this makes it even stiffer.

For this reason, a criteria will be addressed which introduces the critical force to see whether tension or weight is dominated in the horizontal section of the wellbore.

If we assume the tensile force is dominant and with a good approximation, the pipe will be assumed weightless, it will bend toward the sidewall and the normal force can be written as:

$$
F_{x}=F \cdot \sin \left(\frac{\theta}{2}\right)+(F+\Delta F) \cdot \sin \left(\frac{\theta}{2}\right)=2 F \cdot \sin \left(\frac{\theta}{2}\right)+\Delta F \cdot \sin \left(\frac{\theta}{2}\right) \approx 2 F \cdot \sin \left(\frac{\theta}{2}\right)
$$

In above equation the term $\Delta F \cdot \sin \left(\frac{\theta}{2}\right)$ is very small and could be neglected.

If we assume weight is dominant, the pipe will lie on the bottom side of the wellbore. In this condition with a good approximation, there is no tension force and simply the normal force will become:

$$
F_{x}=W \cdot \Delta L \cdot \sin \alpha
$$

For the critical value, we assume equations (1) and (2) are equal and hence:

$$
\begin{gathered}
\frac{F_{x}}{\Delta L}\left[\frac{K N}{m}\right]=W\left[\frac{K N}{m}\right] \cdot \sin \alpha \\
F=\frac{W \cdot \Delta L \cdot \sin \alpha}{2 \sin \left(\frac{\theta}{2}\right)}
\end{gathered}
$$

With introducing this term to the new model, we could greatly improve the under-prediction, which occurred when the effect of the weight especially BHA in the horizontal section has not been considered in the friction model.

\section{Field Cases}

\subsection{Case Study I}

The field data of a single run of drilling of a wellbore has been analysed. It is an ERD well with two build sections. Right after kick-off point the first build section will start then the trajectory will be held and again building the angle for the second time to have a 90 degree inclination at the end of this section continuing to horizontal section all the way through the formation. The last $350 \mathrm{~m}$ of this run is on drilling mode. So with this analysis we could investigate the whole three modes which are pipe slack-off, pipe pick-up and drilling. In this run also we had some sections that has been reamed and circulated. This means that we could also analyze the friction in that specific section which we have both up/down and rotation together. This effect has been addressed in the new model of Aadnoy et al. (2009) and had not been addressed in the previous models.

\subsubsection{Wellbore trajectory profile}

The well that has been considered for friction analysis is an offshore well in the North Sea. A single run in the reservoir section has been considered. The well start vertically with a kick-off point of approximately $350 \mathrm{mMD}$ and a first build section from kick-off point to $1200 \mathrm{mMD}$. Then the angle of this build will be held at almost $30^{\circ} \pm 2^{\circ}$ inclination until $2750 \mathrm{mMD}$. From this depth the second build section starts to build the angle from $30^{\circ} \pm 2^{\circ}$ to $90^{\circ}$ i.e. (horizontal section). Right after the horizontal section will start from $4500 \mathrm{mMD}$ to the end. This well profile is a very good example for friction analysis as all different sections of well geometry exist including straight inclined, curved and horizontal sections. Fig. 4 shows the geometry of the well under consideration with casing shoe positions. For the run that we evaluate, the $95 / 8$ " casing is set at $3207 \mathrm{mMD}$ with an open-hole section to TD at $5247 \mathrm{mMD}$, and where the last $360 \mathrm{~m}$ were drilled. As a result we will investigate the friction analysis for three conditions of running in hole (RIH), tripping-out and drilling. 


\subsubsection{Tripping out}

Fig. 5 shows the pick-up plot for this run. We start bottoms-up calculations with taking $100 \mathrm{~m}$ element from bottom-hole all the way up to the surface. We repeat the calculations for different friction coefficients. We considered two different cases for friction coefficients. First we assumed a single value for whole borehole. We changed the friction factor for $0.2,0.3$ and 0.4 . For the second case we assumed different friction factors for open-hole and cased- hole sections. We kept the friction factor for the cased hole to 0.2 and changed the value to $0.2,0.3$ and 0.4 for open-hole. As it is clearly shown in the plot, the three models are perfectly matching the field data except for a hump that has been occurred from $2180 \mathrm{mMD}$ to $3140 \mathrm{mMD}$. This section is a build section which starts with $30^{\circ}$ and ends with $55^{\circ}$. Right after this section is casing shoe.

The models cannot predict the local increase in hook load, but there are some possible effects that should be further investigated. One reason is that it is a result of well geometry. In this interval there is a build section and building an angle of almost $25^{\circ}$ over $960 \mathrm{mMD}$ interval. Once the soft string models are applying and as they assume the pipe as a cable that lying on high or low side of the borehole wall completely, the friction force will be affected rather than to consider a stiff string that tolerate a bending moment in the bend sections.

The other reason could be due to cuttings accumulation. It means that any time that the pumps are off and cuttings begin to settle, the cuttings will not be stable until they have landed in the lower part of the intermediate build section. In this section, the problem is that after getting to the casing shoe i.e. where there is already extra cuttings accumulated owing to the increased annular diameter), the well has been circulated, but only one bottoms up. This is used to be a normal procedure because the general belief is that once inside casing everything will be fine. Actually one bottoms up won't evacuate the cuttings from a cased hole at these inclination. So after circulating one bottoms up, an annulus still quite full of cuttings will unload and the result is an avalanche down onto the top of the BHA; obviously not enough to pack off, but it may be enough cuttings to cause the increased friction as it can be seen in hump\#1 section.

The second small hump\#2 could be predicted by models, here is near heel section and the cuttings bed that could be removed by a single bottom-up waiting for the BHA to be dragged into. The models of course could not predict the cuttings bed. As a result it would be due to well geometry.

\subsubsection{Running in hole}

For the case of RIH if the models with the same conditions used in the POOH applied it will result in complete mistake. In the case of RIH, in some well the float valve is used. In this case the drillstring will be filled up with the drilling fluid a few times throughout the whole well interval. How long it takes to be filled-up again depending on the collapse strength of the pipe. In this well the pipes are filling almost every $1000 \mathrm{mMD}$ of running in. As you could see in Fig. 7 in this case in each section that well is being filled up with mud there is a jump in the hook load and this jump is equal to the weight of the mud that has filled the pipe.

\subsubsection{The buoyancy effect}

In other words when the inside of the pipe is empty and there is mud on the outside, the buoyancy factor is completely different than for the case of both inside and outside are filled with mud. Aadnoy and Kaarstad (2006) developed the equations to calculate the buoyancy factor for the cases when there are different fluids densities inside and outside drillpipe. The standard buoyancy factor is given by the following equation:

$$
\beta=1-\frac{\rho_{\text {mud }}}{\rho_{\text {pipe }}}
$$

Otherwise, having different fluid density on inside/outside of the drill string, equation (5) is applicable,

$$
\beta=1-\frac{\rho_{o} r_{o}^{2}-\rho_{i} r_{i}^{2}}{\rho_{\text {pipe }}\left(r_{o}^{2}-r_{i}^{2}\right)}
$$

And for a string composed of different pipe sizes with different unit weights, the overall buoyancy factor for the entire composite string is as follows: 


$$
\beta=1-\frac{\sum_{i=1}^{k} D_{k}\left(\rho_{o} r_{o}^{2}-\rho_{i} r_{i}^{2}\right)}{\rho_{\text {pipe }} \sum_{i=1}^{k} D_{k}\left(r_{o}^{2}-r_{i}^{2}\right)}
$$

Whenever a float valve is used, and drill string is not completely filled with mud, the overall buoyancy factor has to be applied. Based on equation (6) a single buoyancy factor in the POOH case should be replaced by buoyancy factor profile in this case. This will greatly influence buoyed weight of the string in the wellbore and hook load and torque consequently. For this case study following buoyancy profile has been calculated in order to be used in the models to come up with hook load in tripping in situation. Fig. 6 shows the buoyancy profile while tripping-in in this well.

As it is shown clearly in Fig. 7 is the step changes in the field data are the results of changes in buoyed weight of the pipe while it is empty or filling with the mud. This demonstrates the importance of handling the buoyancy effect correctly.

This plot consists of two parts; from the surface to $2990 \mathrm{mMD}$ and from this depth to the end. Hook load analysis for tripping out gave a good match between measured data and models using a friction coefficient of 0.2. Using the same friction coefficient for RIH gives a perfect match in the first $3000 \mathrm{mMD}$. But from this depth a discrepancy between the field and models can be observed.

As it is also clearly shown in Fig. 8 which is a back calculation of friction factor from field data, the pick-up friction factor is almost 0.2 everywhere except the interval that we introduced as hump\#1 in Fig. $\mathbf{5}$ and explained the possible reasons could be behind that. Tripping-in graph shows that friction factor is close to 0.2 in the upper interval above $3000 \mathrm{mMD}$, but for the interval between $3000 \mathrm{mMD}$ and $3500 \mathrm{mMD}$ the friction factor starts to decrease gradually from 0.2 to 0.1 . This means that something unusual in occurring in this interval. We applied the same friction factors as well through this interval and changed it gradually from 0.2 to 0.1 . From the depth $3500 \mathrm{mMD}$ to the $4890 \mathrm{mMD}$ the friction factor is almost 0.1 and this means that the friction force is decreasing in this section while this is not the case for the tripping-out analysis. This is where assessing the axial forces on the pipe is important whether the pipe is in tension or compression. With looking at the pick-up data it is observable that drillstring is fully in tension while it is tripping throughout the wellbore. This means that the pipe is fully on high side of the wellbore and assumption of the soft-string models which have been used is valid.

The tripping-in pipe conditions is much more complex. As it has been analysed, the section started from 3200 $\mathrm{mMD}$ is in compression while the interval above this depth, pipe is in tension. Because the pipe is narrowly is changing between tension and compression and the pipe is neither on low side nor high side and a pseudo-catenary (Aadnoy et. al. 2006) profile is forming and the friction is reduced dramatically as the contact force is diminishing and this is where the normal soft-string models could not predict. The friction force reduction is clearly visible with matching the field data with models with friction factor of 0.1 .

Another effect that can be addressed is the acceleration of the BHA. Every time one stand has been run in hole, the string is stopped for connection. Consequently, the BHA has to be de-accelerated to stop. The effect of this de-acceleration will be a peak on the hook load every time the drill string is stopped for connection. Zooming in on Fig. 7 shows that the visible peaks on the hook load are spaced by about $30 \mathrm{~m}$. Also, note that when comparing Figures 5 and 7 the peaks are larger for RIH than for tripping out. This is what should be expected considering the direction in which the de-acceleration of the BHA takes place.

\subsubsection{Drilling}

During this run $360 \mathrm{~m}$ of new formation were drilled. The hook load during drilling composes the last $360 \mathrm{~m}$ of the hook load shown in Fig. 7. During drilling tangential friction (i.e. torque) will dominate over axial friction. The result being that the effective friction coefficient in axial direction is reduced, and the hook load will increase towards static weight. The ratio between the axial and tangential friction can be calculated based on RPM, ROP and pipe diameters (Aadnoy, Fazaeli and Hareland, 2009). However, the calculated ratio should always be calibrated against real data. Therefore, hook load during drilling from different depth intervals would be desirable for good calibration.

The reason why calibration is required is that the axial tension of the drill string during drilling is different from $\mathrm{RIH}$ and tripping out. When the effect of the well path is significant, such as for this well, the axial tension will affect the average friction force in the well. Thus, the average friction coefficient during drilling can differ from the values observed during RIH and tripping out. Fig. 8 shows that the effective axial friction coefficient is reduced to approximately 0.05 during drilling. 


\subsection{Case Study II}

\subsubsection{Well Trajectory Profile}

This well is a well in North Sea. The total measured depth of this well is $4948 \mathrm{mMD}$ and True Vertical Depth of this well is $1580.44 \mathrm{~m}$. This well has been designed to be a single build section after kick-off point following by a long horizontal section.

The KOP of this well is $415 \mathrm{mMD}$ and the build section is from this depth to $2308.4 \mathrm{mMD}$ and from this point forward until the target, which is $4948 \mathrm{mMD}$, is the long horizontal section. This well actually is a typical of shallow wells with long horizontal section. There is quite considerable side turn in the horizontal section that is of our interest to be analyzed from friction prospective. This case study is a well with quite a few turns in the horizontal section. The point is that do the different models could grasp effect of the change in azimuth? The discussion is that in the long horizontal section there are quite big turns. Fig. 9 shows the wellbore profile and azimuth and inclination change of the well under consideration.

\subsubsection{Tripping out}

The run under consideration for drag analysis is the one that the bit is tripping out from $4567.79 \mathrm{mMD}$ to the surface. We performed the bottoms-up calculation for this well and we performed calculations with different friction coefficients $0.1,0.15,0.18,0.2,0.25,0.3$ and 0.4 . The sensitivity analysis on different friction coefficients has been done in order to find the closest match with the field data.

The models reveal that from the depth approximately $2500 \mathrm{mMD}$ the deviation from the field data starts. With a careful look at the azimuth change in the well profile, it could be seen that more than $70^{\circ}$ azimuth change has happened between 3000- $4000 \mathrm{mMD}$ in the well profile.

Fig. 10 shows the friction factor back calculation from the field data. As it can be seen from the graph, friction coefficient of 0.2 is the friction factor we are expecting to match with model. The extra friction factors from $2500 \mathrm{mMD}$ to $4000 \mathrm{mMD}$ is due to high turns in the well path which promote friction in the wellbore specially when stiff string i.e. BHA is dragged up in the wellbore. The BHA in this well is a packed one with eight stabilizers in $128 \mathrm{~m}$ length. Moreover, as Fig. 11 shows higher hoisting speed in the interval of $2500 \mathrm{~m}-4000 \mathrm{~m}$ i.e. $28 \mathrm{~m} / \mathrm{min}$ compared with the lower interval below $4000 \mathrm{~m}$ i.e. $7 \mathrm{~m} / \mathrm{min}$. This brings about a higher friction factor because of pulling full-gauged BHA with higher speed. The drilling fluid that is moving down as the pipe is moving up does not have enough clearance to pass and this creates some friction in the wellbore. The lines with different colors are average hoisting speeds throughout the well at different sections. In addition the lower friction values below $4000 \mathrm{~m}$ is due to much lower tripping speed (i.e. almost a quarter of the section $2500 \mathrm{~m}-4000 \mathrm{~m}$ ) and also the azimuth change in this part of horizontal section is much less than the section above. These two factors together brought about lower friction values in the last section of the wellbore.

Fig. 12 shows the hoisting plot for models versus field data comparison. The best match between modified new model and field data is taking place at friction coefficient of 0.2 while Johancsik model overpredicts friction of this specific wellbore profile.

\subsubsection{Tripping in}

For this case study, the run, which is from surface to the $3017 \mathrm{mMD}$, has been considered. The important point in that there are three step changes in the lowering hookload plot. These step changes are because the pipe is lowered to a certain depth and then is filled-up with mud not to exceed collapse pressure of the pipe. In this case, inside the pipe is air and outside is mud and the overall buoyancy factor cannot be applied. Aadnoy and Kaarstad (2006) developed the equation to calculate buoyancy factor when there are different fluids inside and outside drillpipe. For this reason, the buoyed weight of the pipe is different from point to point while lowering the pipe inside the borehole. Fig. 13 shows the buoyancy profile of the run for this well. The drillstring was filled-up with drilling fluid at depths $1018 \mathrm{mMD}, 2202 \mathrm{mMD}$ and $3017 \mathrm{mMD}$. Usually the wells in North Sea are filled-up every $1000 \mathrm{mMD}$.

Based on Fig. 13 a single buoyancy factor in the $\mathrm{POOH}$ case should be replaced by buoyancy factor profile given in this plot for RIH.

The same as what we did for hoisting friction, the hook load while tripping-in and the best match between field data and modified model took place at friction coefficient $=0.2$. Fig. 14 shows the lowering hookload plot along with the models. Here the new model applied once for real 3D well and once with 2D well while keeping azimuth constant. There is not much difference between these two friction curves except from the heel until final lowering depth where side turns in the horizontal sections affect friction. When the weight effect explained 
above, is introduced into the model and the amplification of the friction in the horizontal section captures, then this modified model perfectly match with the field data from surface down to the final lowering depth. The Johancsik (1987) model also has been applied and calculated for the well under consideration. This was done to have an idea of the model, which is used, in most of simulators nowadays.

The comparison of the modified model and Johancsik model shows that the modified model could match at friction factor of 0.2 while Johancsik model could match with much lower value that is not realistic. This means that our model seems to have a more realistic picture of the friction and Johancsik model has overprediction of friction and has to be modified. Moreover, the modified model gives the same friction factor i.e. 0.2 for both tripping-in and tripping-out friction analysis.

\subsubsection{Drilling}

Drilling took place from $3017 \mathrm{mMD}$ to $4948 \mathrm{mMD}$. During the drilling operation, the rotational speed is much higher than axial speed; hence, the axial friction is reduced significantly. In other words the axial friction i.e. drag is not a concern and rotational friction i.e. torque will be important to be considered.

Moreover, during drilling operation the axial friction will be reduced dramatically. This effect has been introduced by an angle, which is defined to be proportionality of the hoisting/lowering speed to the tangential speed due to rotation (Aadnoy et. al. 2009). Also Mirhaj et. al. (2010) has analyzed a field case study that back-calculated the friction factor during drilling from field hook load and the result showed a friction factor of 0.05 for drilling interval while it was 0.2 for lowering and hoisting in that well. In this field, study also is in agreement with the angle and previous case study and a friction coefficient of 0.01 is needed to give a good match of the field and models data.

Aadnoy et. al. (2009) introduced a new model for combined axial and rotational motion of the drillstring (i.e. drilling) which introduces a sin $\psi$ in the equations of the straight sections and curved sections. During drilling, because the axial motion i.e. ROP respect to rotational speed (RPM) is much slower, $\psi$ angle will be very small and sin $\psi$ is small. This is in a good agreement with matching friction coefficient we calculated from other models.

The friction coefficient of 0.01 will reduce the effect of bend that exist in the same interval during hoisting. This is the reason that the modified new model and Johancsik model are all very close and are in good agreement with field data.

Fig. 15 shows the comparison of the field data and models for drilling interval. Due to friction in the wellbore always, there are some weight losses from surface to the bit and this means that the whole weight applying at the surface will not be transferred to the bit. This weight loss will be determined by using a friction model (Aadnoy et. al. 2001). For simplicity, we assumed that whole weight on bit at surface would be transferred to the bit.

\section{Conclusion}

The following conclusion has been taken from this work:

- The three different models applied in this study are shown to be consistent and give a close match. However, the new model has proved to handle a 3D dogleg in a much simpler way.

- The friction analysis inside the wellbore should be carefully performed. Correct assessment of buoyancy and the effect of the well path are shown to be critical for calibrating the friction coefficient.

- The friction force analysis demonstrates the difference between rotating the string and not rotating the string. Rotation not only changes the direction of friction force, it also results in a change of axial tension that may change the total friction. Proper calibration is required to determine the effective friction coefficient.

- The side turn in the horizontal section will have contribution to the friction force. This is even much more when BHA is dragging into the big side turn up/down. Because soft string models cannot capture the stiffness and bending moment of the pipe, which contribute to the normal force and hence amplify the friction in the wellbore while tripping in/out.

- During hoisting and lowering operations, the correct position of the pipe in the wellbore especially in side turns is complex and depending on the position, the forces acting on the pipe are whether tension or 
weight dominated. The effect of weight in the side bends of horizontal sections is very crucial in friction prognosis in the wellbore. This effect is more important in wells with long horizontal sections including considerable side bends inside the horizontal section.

- The case study above showed that following criterion

$\checkmark$ tripping speed

$\checkmark$ hydraulic effects

$\checkmark$ stiffness

$\checkmark$ piston effect of packed stabilizers in BHA

have considerable effects on friction in the wellbore that are not taken into account in our friction model as well as other industrial soft wares. The effect of these parameters has to be performed in future studies.

\section{Nomenclature}

$F_{n}=$ Normal contact force, $\mathrm{N}$

$F_{t}=$ Tensile force, $\mathrm{N}$

$F_{x}=$ normal contact force, $\mathrm{KN}$

$F=$ tensile force, $\mathrm{KN}$

$\Delta F=$ increase in tension over element length, $\mathrm{KN}$

$W=$ Weight of the pipe, $\mathrm{N}$

$\alpha=$ Inclination angle, degree

$\theta=\quad$ Dogleg angle, degree

$\mu=$ Friction Coefficient, dimensionless

$M=$ Torque, N.m

$R=\quad$ Adjusted pipe radius, $\mathrm{m}$

$B=$ Buoyancy factor, dimensionless

$\rho_{\text {mud }}=$ Mud Density, S.G.

$\rho_{\text {pipe }}=$ Pipe Density, S.G.

$\rho_{o}=$ Outside pipe mud density, S.G.

$\rho_{i}=$ Inside pipe mud density, S.G.

$r_{o}=$ Outer pipe radius, $\mathrm{m}$

$r_{i}=\quad$ inner pipe radius, $\mathrm{m}$

$D_{k}=$ True Vertical Depth, $\mathrm{m}$

\section{Acknowledgement}

We would like to acknowledge NSERC, Talisman and Pason for provision of parts of financial supports for this research at the University of Calgary. I am also thankful of Ben Hern and Frode Robberstad from Statoil for providing us required data along with very valuable discussions we had together. I also would like to thank Morten Gjertsen and Frank Johnsen from Baker Hughes for providing us required data for second case study along with concrete discussions on the subject. 


\section{References}

Aadnoy, B.S., Fazaelizadeh, M., Hareland, G. (2010). "A 3-Dimensional Analytical Model for Wellbore Friction”, Journal of Canadian Petroleum Technology, 2010.

Aadnoy, B.S., Andersen, K. (2001). "Design of Oil Wells Using Analytical Friction Models", Journal of Petroleum Science and Engineering, September 2001.

Aadnoy, B.S., Djurhuus, J. (2008). "Theory and Application of a New Generalized Model for Torque and Drag", SPE/IADC 114684 presented at the SPE/IADC Asia Pacific Drilling Technology Conference and Exhibition, Jakarta, Indonesia, August 2008.

Aadnoy, B.S., Fabiri, V.T., Djurhuus, J. (2006). "Construction of Ultralong Wells Using a Catenary Well Profile”, SPE/IADC 98890 presented at the SPE/IADC Drilling Conference, Miami, February 2006.

Aadnoy, B.S., Larsen, K. and Berg, P.C. (1999). "Analysis of Stuck-Pipe in Deviated Boreholes". SPE 56628 presented at the SPE Annual Technical Conf. and Exhibition, Houston, Texas, October 1999.

Aadnoy, B.S. (1998). "Friction Analysis for Long-Reach Wells", SPE/IADC 39391 presented at SPE/IADC Drilling Conference, Dallas, Texas, March 1998.

Aadnoy, B.S., Kaarstad, E. (2006). "Theory and Application of Buoyancy in Wells", SPE/IADC 101795 presented at the SPE/IADC Asia Pacific Drilling Technology Conference and Exhibition, Bangkok, Thailand, November 2006.

Aarrestad, T.V. (1990). "Effect of Steerable BHA on Drag and Torque in Wells", SPE 20929 presented at Europec 90, The Hague, Netherlands, October 1990.

Aarrestad, T.V., Blikra, H. (1994). "Torque and Drag- Two Factors in Extended-Reach Drilling”, Journal of Petroleum Technology, September 1994.

Alfsen, T.E., Blikra, H., Tjotta, H. (1993). "Pushing the Limits for Extended-Reach Drilling, New World Record Well from Platform Statfjord C, Well C2" SPE 26350 presented at the SPE Annual Technical Conference and Exhibition, Houston, October 1993.

Anston, M.S., Hearn, P.J., McGhee, G. (1998). "Techniques for Solving Torque and Drag Problems in Today's Drilling Environment", SPE 48939 presented at the Annual Technical Conference and Exhibition, New Orleans, Louisiana, September 1998.

Banks, S.M., Hogg, T.W. and Thorogood, J.L. (1992). "Increasing Extended-Reach Capabilities Through Wellbore Profile Optimization", SPE/IADC 23850 presented at SPE/IADC Drilling Conference, New Orleans, Louisiana, January 1992.

Brett, J.F., Beckett, A.D., Holt, C.A., Smith, D.L. (1989). 'Uses and Limitations of Drillstring Tension and Torque Models for Monitoring Hole Conditions", SPE Drilling Engineering, September 1989.

Falconer, I.G., Belaskie, J.P., Variava, F. (1989). "Applications of a Real Time Wellbore Friction Analysis", SPE/IADC 18649 presented at the SPE/IADC Drilling Conference, New Orleans, Louisiana, February-March 1989.

Fazaelizadeh, M., Hareland, G., Aadnoy, B.S., "Application of New 3-D Analytical Model for Directional Wellbore Friction”, Journal of Modern Applied Science, Vol. 4, No. 2, 2010.

He, X., Halsey, G.W., Kyllingstad, A. (1995). "Interactions between Torque and Helical Buckling in Drilling”, Annual Technical Conference \& Exhibition, Dallas, Texas, October 1995.

Ho, H.S. (1988). "An Improved Modeling Program for Computing the Torque and Drag in Directional and Deep Wells", SPE 18047 presented at the Annual Technical Conference and Exhibition, Houston, Texas, October 1988.

Johancsik, C.A., Friesen, D.B., Dawson, R. (1984). "Torque and Drag in Directional Wells- Prediction and Measurement", Journal of Petroleum Technology, June 1984.

Kaarstad, E., Aadnoy, B.S. (2009). "A Study of Temperature Dependent Friction in Wellbore Fluids", SPE/IADC 119768 presented at the SPE/IADC Drilling Conference and Exhibition, Amsterdam, Netherlands, March 2009.

Lesage, M., Falconer, I.G., Wick, C.J. (1988). ’Evaluating Drilling Practice in Deviated Wells with Torque and Weight Data", SPE Drilling Engineering, September 1988. 
Lesso, W.G., Mullens, E., Daudey, J. (1989). "Developing a Platform Strategy and Predicting Torque Losses for Modeled Directional Wells in the Amauligak Field of the Beaufort Sea, Canada", SPE 19550 presented at the Annual Technical Conference and Exhibition, San Antonio, Texas, October 1989.

Li, Z., Liu, X., Zhou, D., Zhang, S. "A Steady Tension-Torque Model for Drillstring in Horizontal Wells", SPE 26295 presented at USMS Conference.

Liu, Xiushan, Samuel, R. (2009). "Catenary Well Profile for Extended and Ultra-Extended Reach Wells", SPE 124313 presented at the Annual Technical Conference and Exhibition, New Orleans, October 2009.

Luke, G.R., Juvkam-Wold, H.C. (1993). "Determination of True Hook Load and Line Tension under Dynamic Conditions", SPE Drilling \& completion, December 1993.

Maidla, E.E., Wojtanowicz, A.K. "Field Comparison of 2-D and 3-D Methods for the Borehole Friction Evaluation in Directional Wells", SPE 16663 presented at the Annual Technical Conference and Exhibition, Dallas, Texas, September 1987.

Maidla, E.E., Wojtanowicz, A.K. (1987). "Field Method of Assessing Borehole Friction for Directional Well Casing", SPE 15696 presented at the Middle East Oil Show, Manama, Bahrain, March 1987.

Maldla, E.E., Wojtanowicz, A.K. (1990). "Laboratory Study of Borehole Friction Factor with a Dynamic-Filtration Apparatus" SPE Drilling Engineering, September 1990.

Mason, C.J., Allen, F.M., Ramirez, A.A., Wolfson, L. (1999). "Casing Running Milestones for Extended-Reach Wells", SPE/IADC 52842 presented at the SPE/IADC Drilling Conference, Amsterdam, Netherlands, March 1999.

Mason, C.J., Chen, D.C.-K. (2007). "Step Changes Needed to Modernize T\&D Software" SPE/IADC 104609 presented at the 2007 SPE/IADC Drilling Conference, Amsterdam, Netherlands, February 2007.

Mirhaj, S.A., Fazaelizadeh, M., Kaarstad, E., Aadnoy, B.S. (2010). "New Aspects of Torque-and-Drag Modeling in Extended Reach Wells", SPE 135719, SPE Annual Technical Conference and Exhibition, Florence, Italy, September 2010.

Mirhaj, S.A., Kaarstad, E., Aadnoy, B.S.,"Minimizing Friction in Shallow Horizontal Wells", SPE 135812, IADC/SPE Asia Pacific Drilling Technology Conference and Exhibition, Ho Chi Minh, Vietnam, November 2010.

Mitchell, R. (2008). "Drillstring Solutions Improve the Torque-Drag Model", SPE/IADC 112623 presented at the SPE/IADC Drilling Conference, Orlando, Florida, March 2008.

Mitchell, R.F. (2008). "Drillstring Solutions Improve the Torque-Drag Model", SPE/IADC 112623 presented at the SPE/IADC Drilling Conference, Orlando, Florida, March 2008.

Mitchell, R.F., Samuel, R. (2009). "How Good Is the Torque/Drag Model?", SPE Drilling \& Completion, March 2009.

Opeyemi, A.A., Pham, S.V. (1998). "A Robust Torque and Drag Analysis Approach for Well Planning and Drillstring Design", SPE/IADC 39321 presented at SPE/IADC Drilling Conference, Dallas, Texas, March 1998.

Paslay, P.R., Bogy, D.B. (1964). "The Stability of a Circular Rod Laterally Constrained to be in Contact with an Inclined Circular Cylinder", Journal of Applied Mechanics. December 1964.

Payne, M.L., Abbassian, F. (1997). "Advanced Torque-and-Drag Considerations in Extended-Reach Wells", SPE Drilling \& Completion, March 1997.

Rao, G., Lesso, W.G., Sapijanskas, M. (2005). "Understanding Torque and Drag: Best Practices and Lessons Learnt from the Captain Field's Extended Reach Wells", SPE/IADC 91854 presented at the SPE/IADC Drilling Conference, Amsterdam, Netherlands, February 2005.

Reiber, F., Vos, B.E., Eide, S.E. (1999). "On-Line Torque \& Drag: A Real - Time Drilling Performance Optimization Tool", SPE/IADC 52836 presented at the SPE/IADC Drilling Conference, Amsterdam, Netherlands, March 1999.

Schamp, J.H., Estes, B.L., Keller, S.R. (2006). ”Torque Reduction Techniques in ERD Wells", SPE/IADC 98969 presented at the SPE/IADC Drilling Conference, Miami, Florida, February 2006.

Sheppard, M.C., Wick, C., Burgess, T. (1987). "Designing Well Paths to Reduce Drag and Torque", SPE Drilling Engineering, December 1987. 
Walker, B.H., Friedman, M.B. (1977). "Three-Dimensional Force and Deflection Analysis of a Variable Cross-Section Drill String”, Journal of Pressure Vessel Technology, May 1977.

Wilson, T.P., Yalcin, O. (1992). "Two Double Azimuth-Double S-Shaped Wells Planned and Drilled Using Torque and Drag Modeling" SPE/IADC 23848 presented at the SPE/IADC Drilling Conference, New Orleans, Louisiana, February 1992.

Zifeng, L., Xingrui, M., Wenhu, H., Xisheng, L. (1996). "A 3D Analysis of a Bottomhole Assembly under Large Deflection”, SPE Drilling \& Completion, June 1996.

Aadnoy, B.S., Fazaelizadeh, M., Hareland, G. (2010). "A 3-Dimensional Analytical Model for Wellbore Friction", Journal of Canadian Petroleum Technology, 2010.

Aadnoy, B.S., Andersen, K. (2001). "Design of Oil Wells Using Analytical Friction Models", Journal of Petroleum Science and Engineering, September 2001.

Aadnoy, B.S., Djurhuus, J. (2008). "Theory and Application of a New Generalized Model for Torque and Drag", SPE/IADC 114684 presented at the SPE/IADC Asia Pacific Drilling Technology Conference and Exhibition, Jakarta, Indonesia, August 2008.

Aadnoy, B.S., Fabiri, V.T., Djurhuus, J. (2006). "Construction of Ultralong Wells Using a Catenary Well Profile", SPE/IADC 98890 presented at the SPE/IADC Drilling Conference, Miami, February 2006.

Aadnoy, B.S., Larsen, K. and Berg, P.C. (1999). "Analysis of Stuck-Pipe in Deviated Boreholes". SPE 56628 presented at the SPE Annual Technical Conf. and Exhibition, Houston, Texas, October 1999.

Aadnoy, B.S. (1998). "Friction Analysis for Long-Reach Wells", SPE/IADC 39391 presented at SPE/IADC Drilling Conference, Dallas, Texas, March 1998.

Aadnoy, B.S., Kaarstad, E. (2006). "Theory and Application of Buoyancy in Wells", SPE/IADC 101795 presented at the SPE/IADC Asia Pacific Drilling Technology Conference and Exhibition, Bangkok, Thailand, November 2006.

Aarrestad, T.V. (1990). "Effect of Steerable BHA on Drag and Torque in Wells", SPE 20929 presented at Europec 90, The Hague, Netherlands, October 1990.

Aarrestad, T.V., Blikra, H. (1994). "Torque and Drag- Two Factors in Extended-Reach Drilling”, Journal of Petroleum Technology, September 1994.

Figures
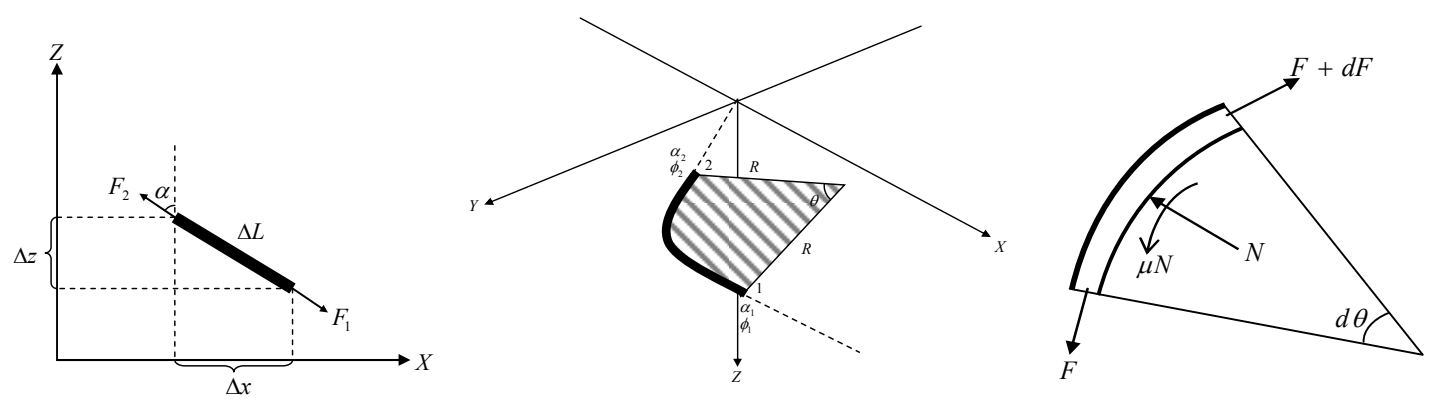

Figure 1. From Left: Dog-leg in 3-D Space, Pipe element along curved section, Pipe element along inclined straight section 


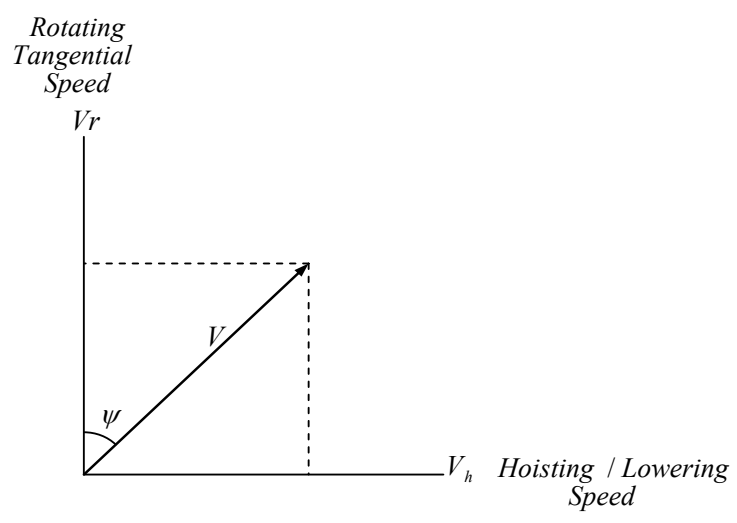

Figure 2. Resultant velocity of axial and tangential velocity

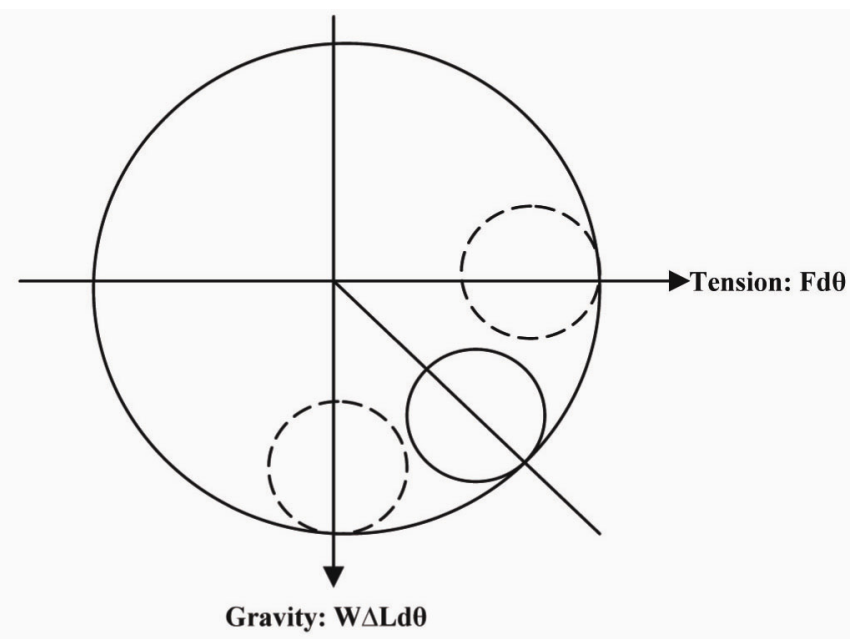

Figure 3. Drillpipe position in the borehole for a side bend
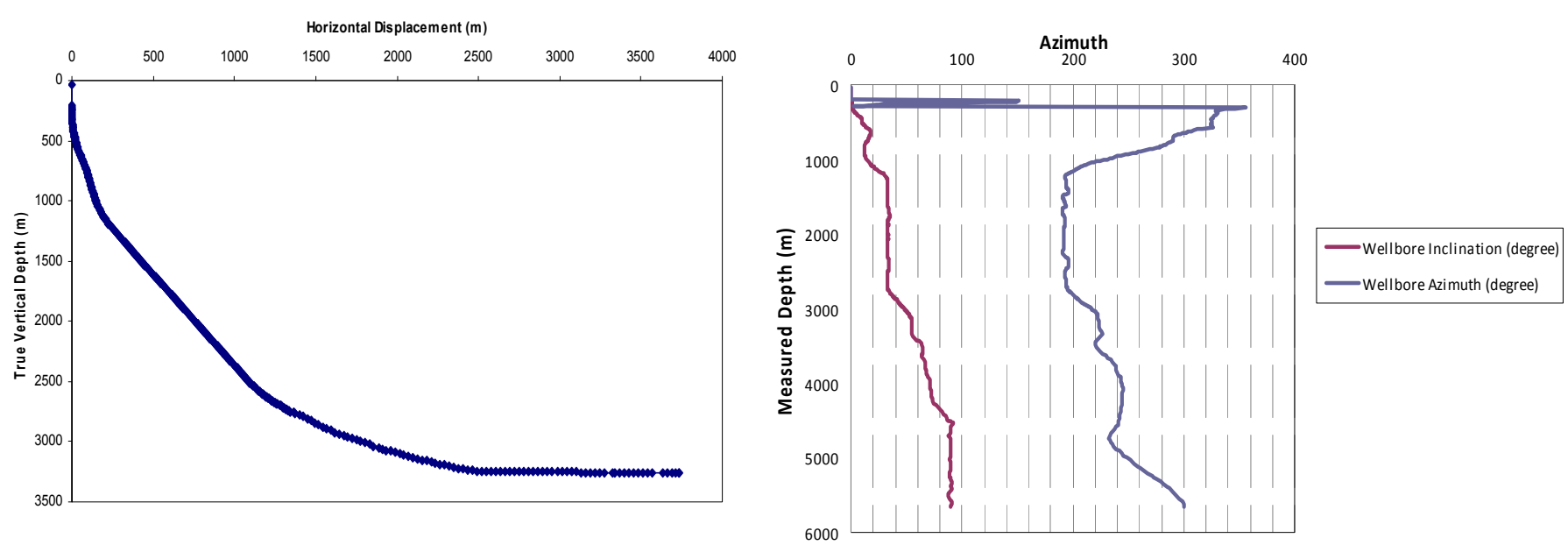

Figure 4. Left: Geometry of North Sea Well, Right: Inclination and azimuth profile from surface to TD of the well 


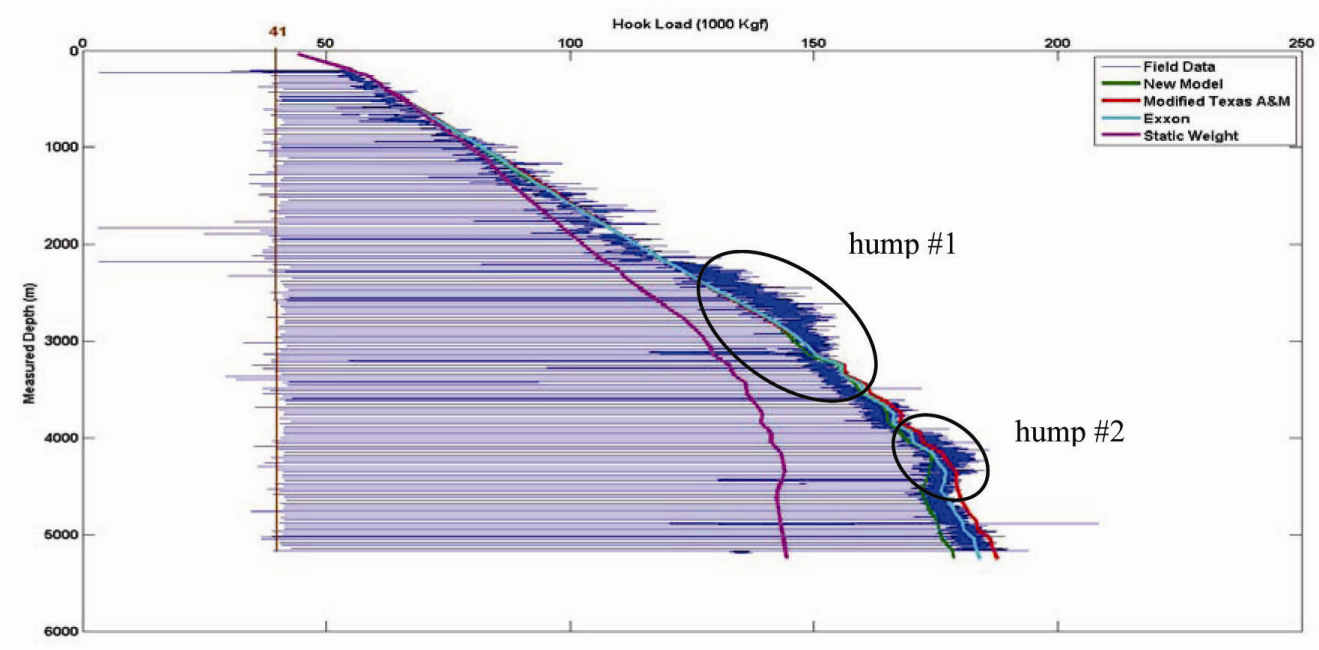

Figure 5. Comparison between field and models hook-load data with friction coefficient $=0.2$ throughout for tripping-out

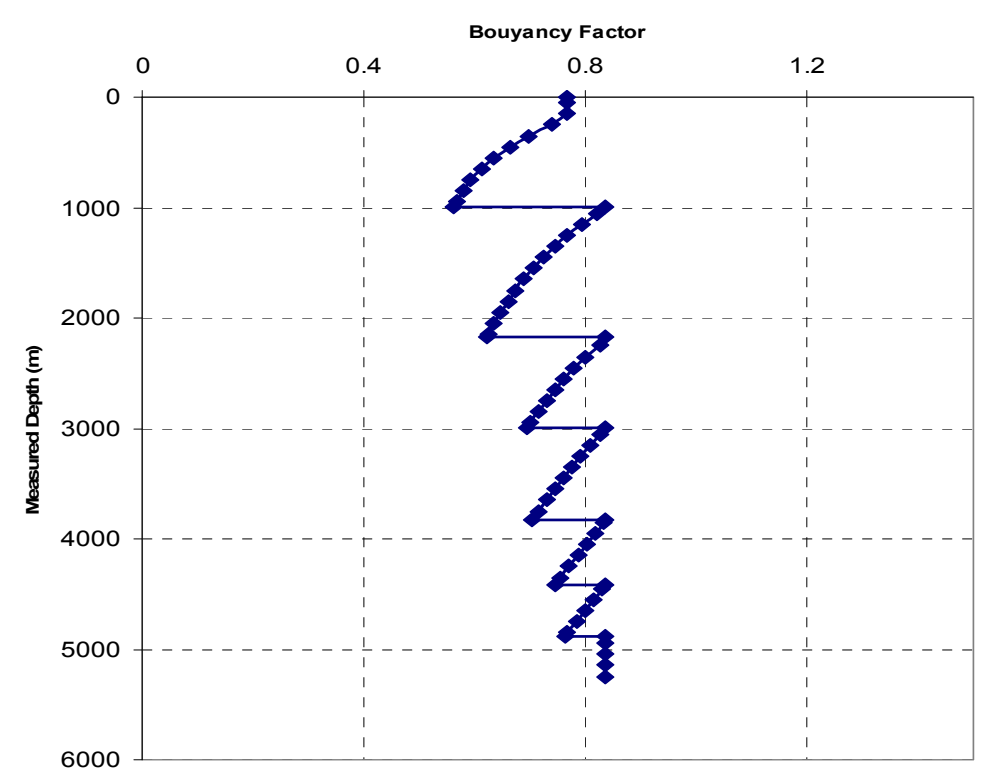

Figure 6. Buoyancy factor profile for well under study while tripping-in 


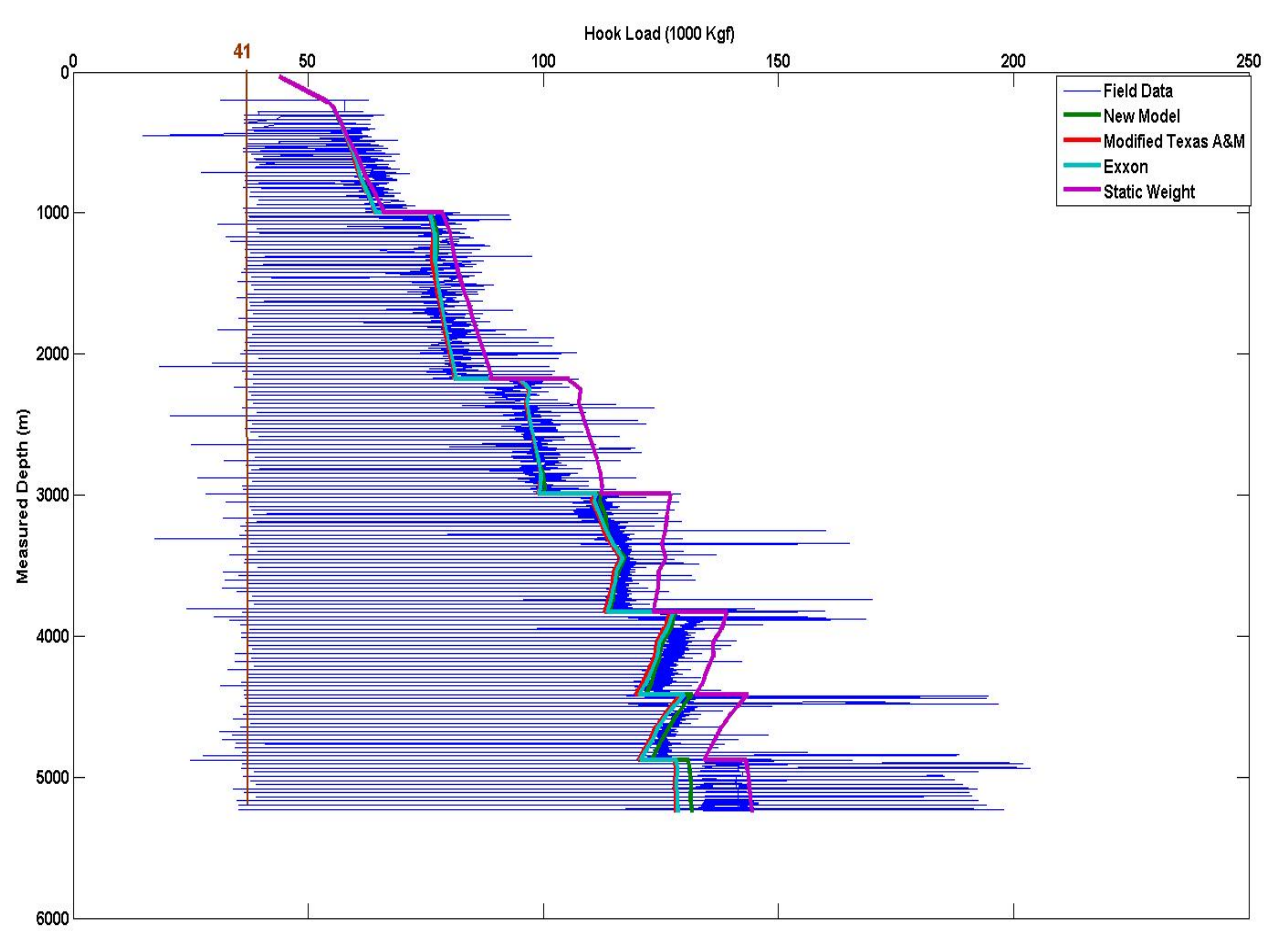

Figure 7. Comparison between field and models hook-load data with using friction coefficient $=0.2$ for tripping-in

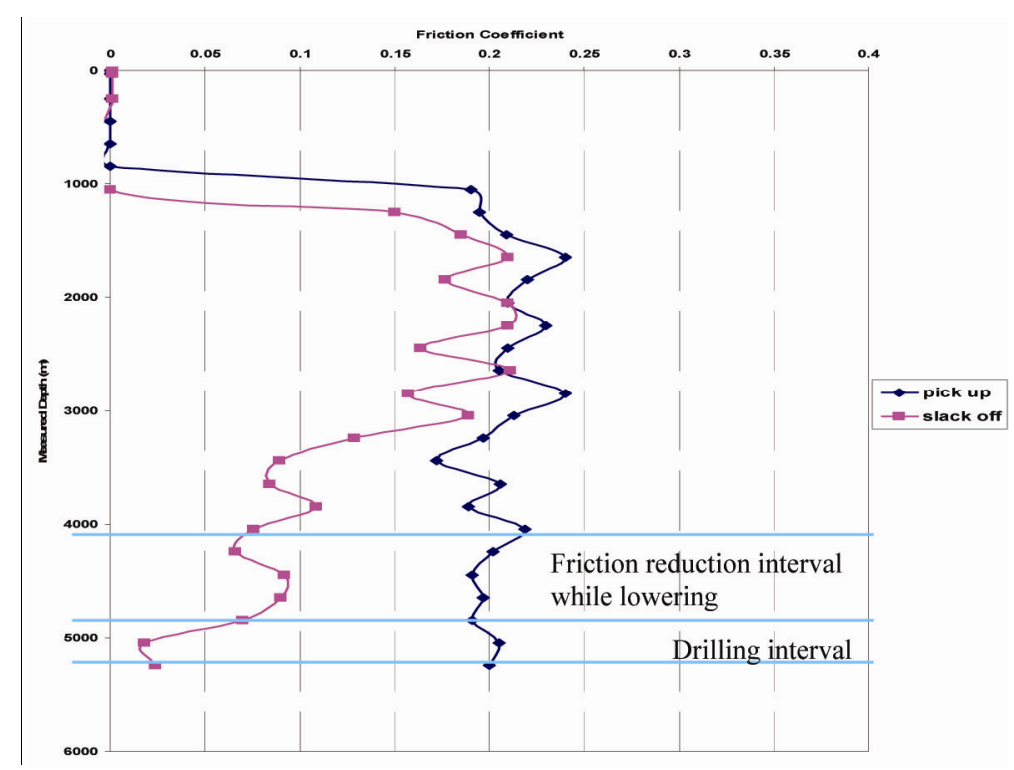

Figure 8 . Sensitivity analysis of friction coefficient vs. measured depth while tripping-in and tripping-out 

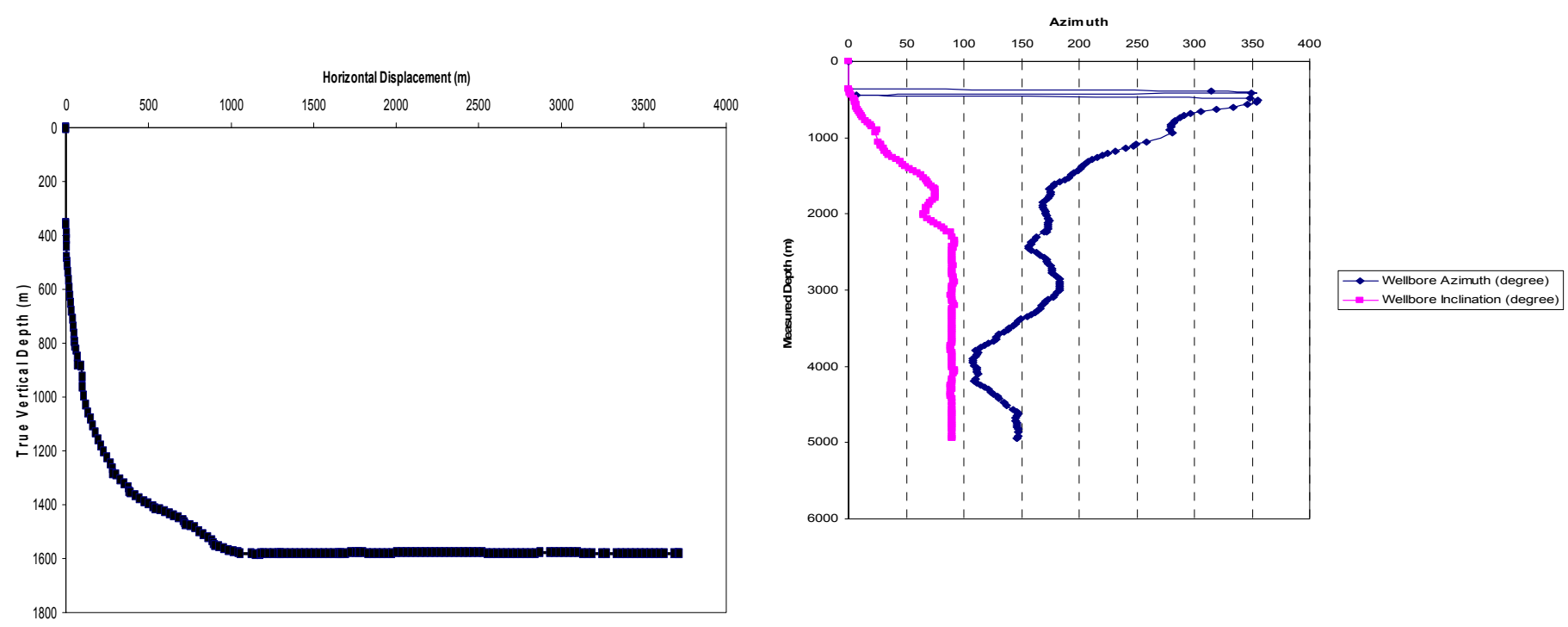

Figure 9. Left: Geometry of North Sea Well, Right: Inclination and azimuth profile from surface to TD of the well

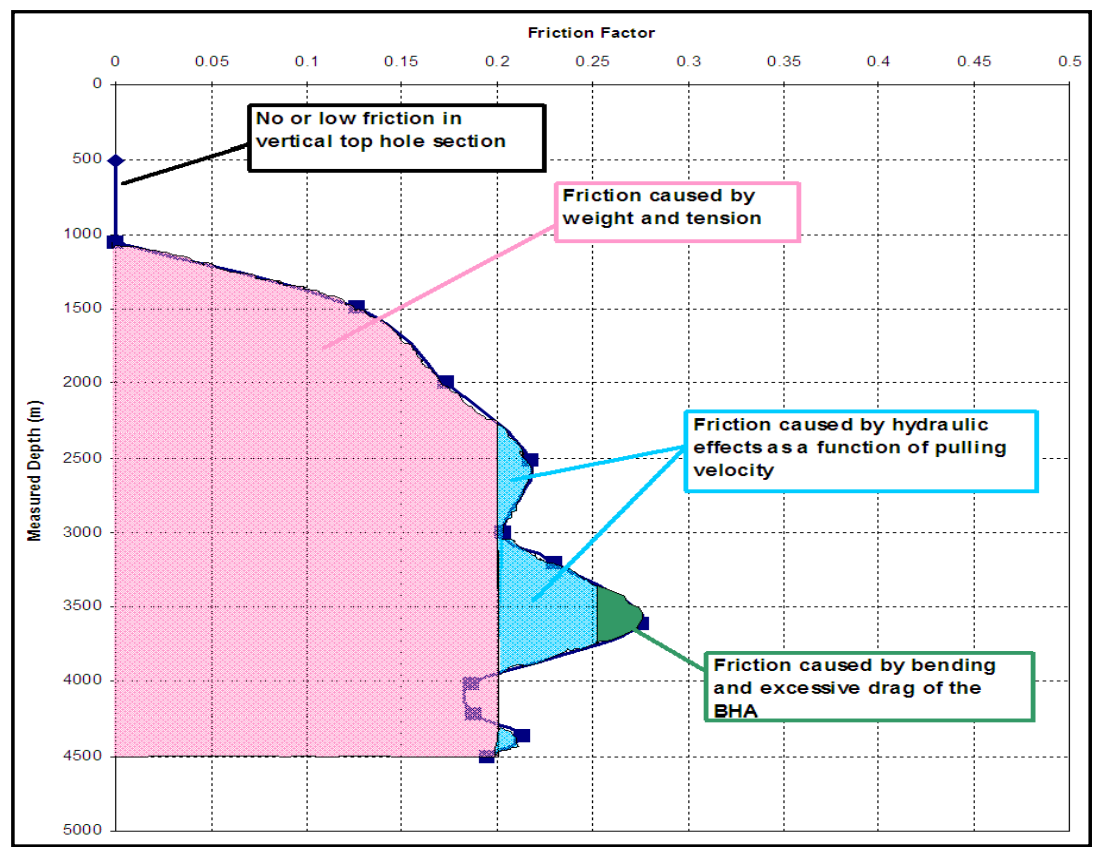

Figure 10. Sensitivity analysis of friction coefficient vs. measured Depth 


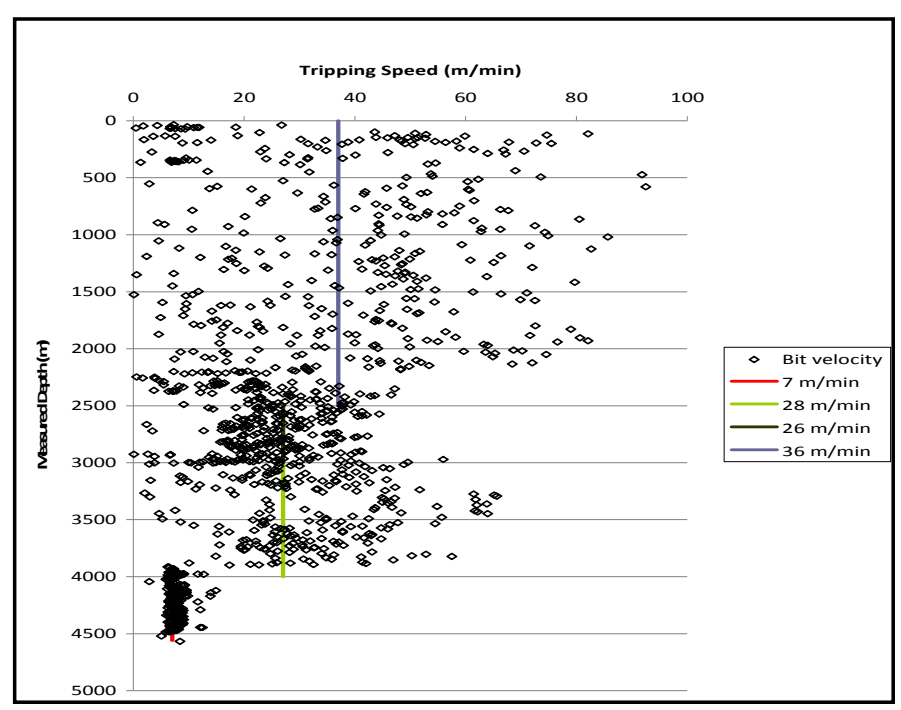

Figure 11. Average hoisting speed for different parts of wellpath

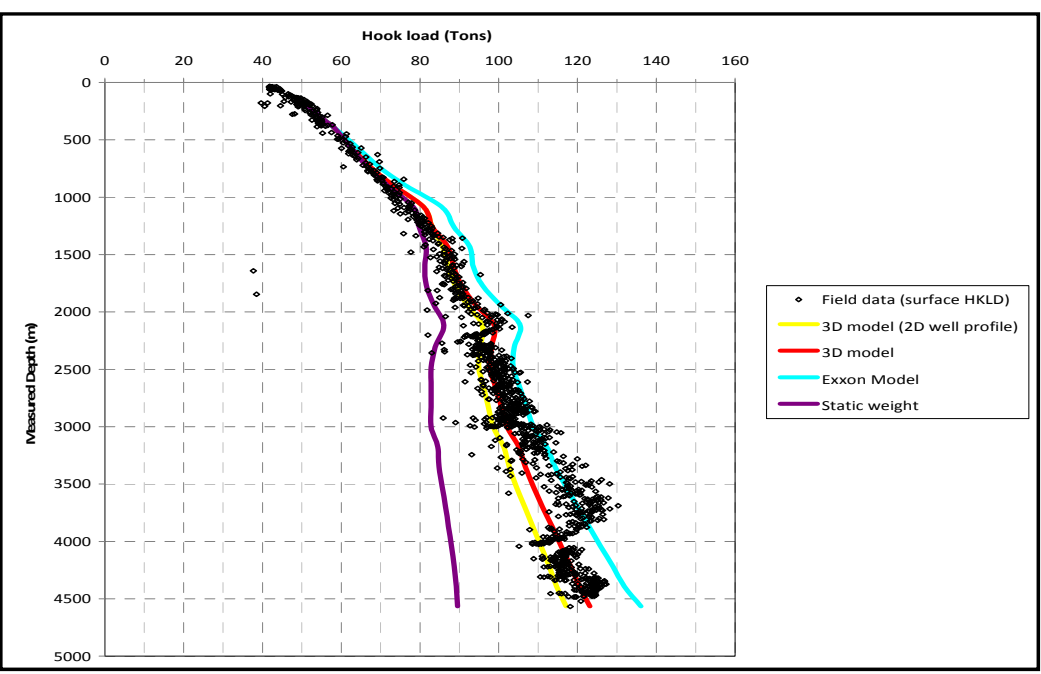

Figure 12. Comparison between field and models hook-load data with using friction coefficient $=0.2$ for tripping-out

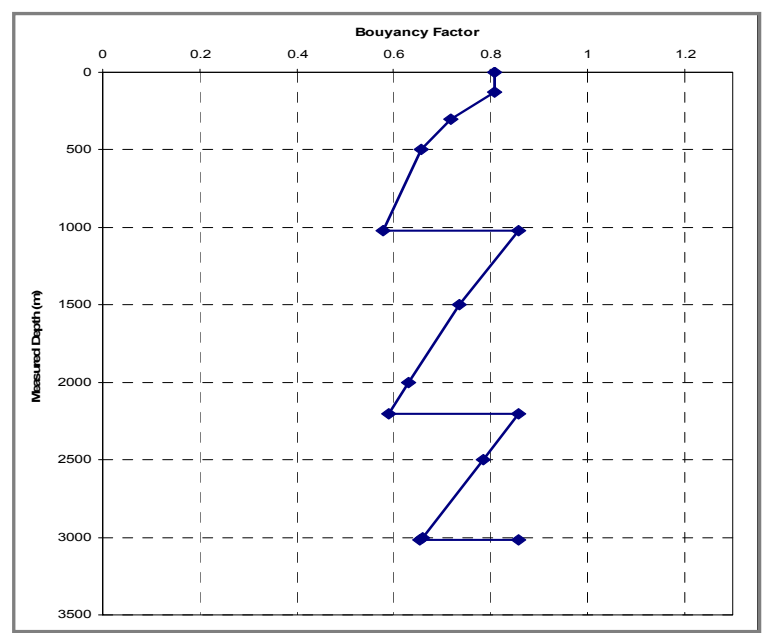

Figure 13. Buoyancy factor profile for well under consideration while RIH 


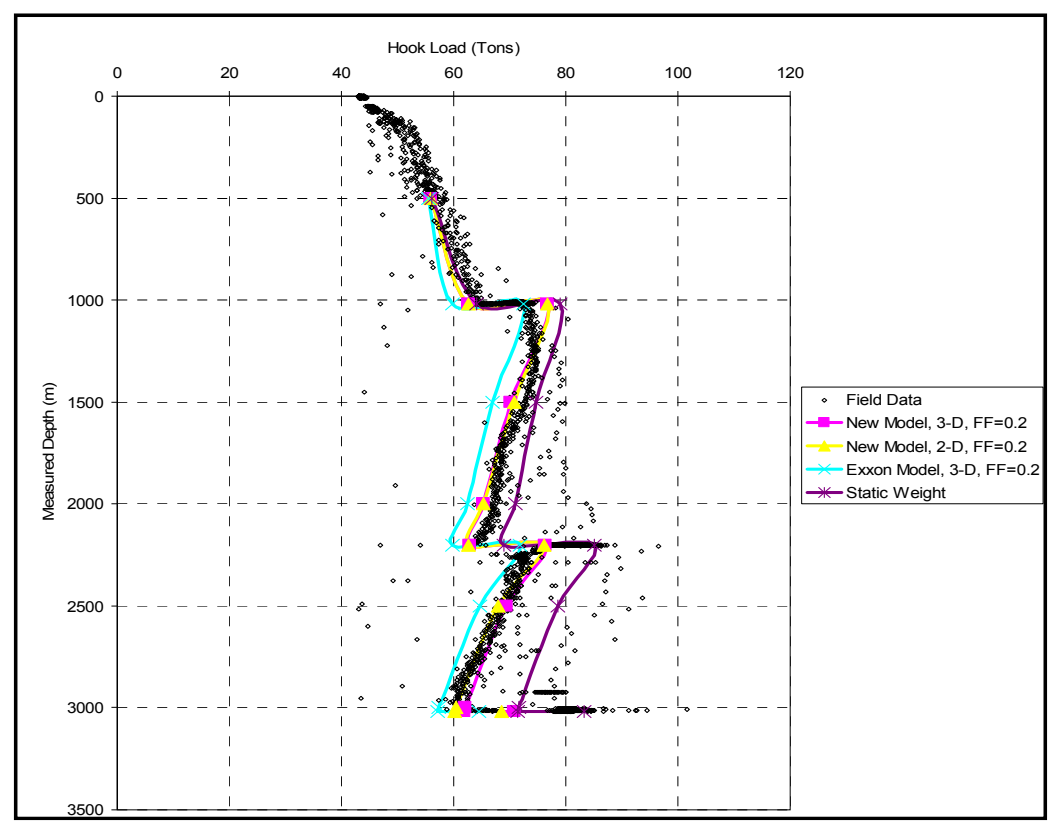

Figure 14. Comparison between field and models hook-load data with using friction coefficient $=0.2$ for tripping-in

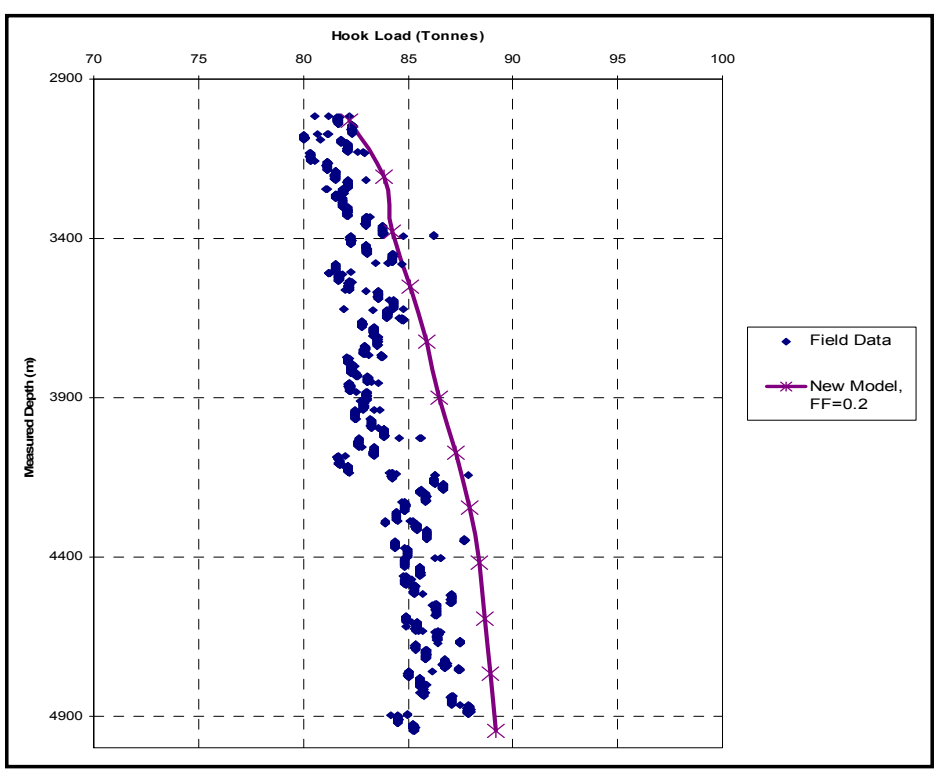

Figure 15. Comparison between field and models hook-load data with using friction coefficient $=0.01$ during drilling 